\title{
A national survey of managed honey bee 2013-2014 annual colony losses in the USA
}

\author{
Kathleen V. LeE ${ }^{1}$, Nathalie SteinhaueR ${ }^{2}$, Karen RenNiCH ${ }^{2}$, Michael E. WILSON ${ }^{3}$, \\ David R. TArpy ${ }^{4}$, Dewey M. Caron ${ }^{5}$, Robyn Rose ${ }^{6}$, Keith S. Delaplane ${ }^{7}$, \\ Kathy Baylis ${ }^{8}$, Eugene J. Lengerich ${ }^{9}$, Jeff Pettis ${ }^{11}$, John A. Skinner ${ }^{3}$, \\ James T. WILKES ${ }^{10}$, Ramesh SAGILI ${ }^{5}$, Dennis VANENGELSDORP ${ }^{2}$, \\ FOR THE BEE INFORMED PARTNERSHIP \\ ${ }^{1}$ Department of Entomology, University of Minnesota, St. Paul, MN 55108, USA \\ ${ }^{2}$ Department of Entomology, University of Maryland, College Park, Plant Science Building, State College, MD 20742, \\ USA \\ ${ }^{3}$ Department of Entomology and Plant Pathology, University of Tennessee, Knoxville, TN 37996, USA \\ ${ }^{4}$ Department of Entomology, North Carolina State University, Raleigh, NC 27695, USA \\ ${ }^{5}$ Department of Horticulture, Oregon State University, Corvallis, OR 97331, USA \\ ${ }^{6}$ USDA Animal and Plant Health Inspection Service, Riverdale, MD 20737, USA \\ ${ }^{7}$ Department of Entomology, University of Georgia, Athens, GA 30602, USA \\ ${ }^{8}$ Department of Agricultural and Consumer Economics, University of Illinois, Urbana-Champaign, IL 61801, USA \\ ${ }^{9}$ Department of Public Health Sciences, Penn State University, Hershey, PA 17033, USA \\ ${ }^{10}$ Department of Computer Science, Appalachian State University, Boone, NC 28608, USA \\ ${ }^{11}$ USDA-ARS Bee Research Laboratory, Beltsville, MD 20705, USA \\ Received 25 July 2014 - Revised 15 December 2014 - Accepted 6 February 2015
}

\begin{abstract}
Honey bee colony losses are a major concern in the USA and across the globe. Long-term data on losses are critical for putting yearly losses in context. US colony loss surveys have been conducted yearly since the winter of 2006-2007. Here, we report the results from the eighth annual survey on winter losses and the second annual survey of summer and annual losses. There were 7425 valid respondents (7123 backyard, 190 sideline, and 112 commercial beekeepers) managing 497,855 colonies, $19 \%$ of the total US colonies. Total losses reported were $19.8 \%$ [95\% CI 19.3-20.3\%] over the summer, $23.7 \%$ [95 \% CI 23.3-24.1\%] over the winter, and $34.1 \%$ [95\% CI 33.6-34.6\%] for the whole year. Average losses were $15.1 \%$ [95 \% CI 14.5-15.7 \%] over the summer, $44.8 \%$ [95\% CI 43.9-45.7\%] over the winter, and 51.1\% [95\% CI 50.2-51.6\%] for the whole year. While total winter loss was one of the lowest reported in 8 years, $66 \%$ of all beekeepers had higher losses than they deemed acceptable.
\end{abstract}

honey bee / survey / mortality / colony losses / USA

\section{INTRODUCTION}

Honey bee (Apis mellifera L.) colony losses are a major concern worldwide. Mortality can be

Electronic supplementary material The online version of this article (doi:10.1007/s13592-015-0356-z) contains supplementary material, which is available to authorized users.

Corresponding author: D. vanEngelsdorp, dennis.vanengelsdorp@gmail.com Manuscript editor: Yves Le Conte driven by a number of interacting factors, including the parasitic mite Varroa destructor, other parasites and diseases, nutrition, pesticides, and socioeconomic factors (Berthoud et al. 2010; Dainat et al. 2012a; Dainat et al. 2012b; Ellis et al. 2010; Le Conte et al. 2010; Potts et al. 2010a; vanEngelsdorp and Meixner 2010). From 1947 to 2008, the total US honey bee population has declined by $61 \%$ (Ellis et al. 2010; vanEngelsdorp and Meixner 2010). In spite of this long-term trend and recent winter losses, the US Department of Agriculture National Agricultural 
Statistics Service (USDA-NASS) estimates that colony numbers increased from 2.39 million in 2006 (USDA-NASS 2007) to 2.64 million in 2013 (USDA-NASS 2014). Colony losses have not resulted in declines, as colony losses can be mitigated by beekeepers splitting colonies to recover or even exceed winter losses, a springtime activity that may mask the severity of a recent winter die-off (vanEngelsdorp and Meixner 2010). In addition, income from record high honey prices (USDA-NASS 2014) and increased compensation for almond pollination in California (vanEngelsdorp and Meixner 2010) provide beekeepers incentives to increase colony numbers. However, it is unclear if beekeepers will be able to sustain this level of annual loss and meet pollination demand while the acreage of pollinatordependent crops continues to increase faster than the honey bee population (Aizen et al. 2008; Aizen and Harder 2009).

Documenting colony losses is critical for putting losses into context and identifying potential causes of mortality, especially in different regions. To better understand the distribution of colony losses, researchers have conducted surveys at national or regional scales (Aston 2010; Brodschneider et al. 2010; Charrière and Neumann 2010; Clermont et al. 2014; Dahle 2010; Gajger et al. 2010; Gray et al. 2010; Hatjina et al. 2010; Ivanova and Petrov 2010; Mutinelli et al. 2010; Neumann and Carreck 2010; Nguyyen et al. 2010; Pirk et al. 2014; Potts et al. 2010b, Soroker et al. 2010; Topolska et al. 2010; van der Zee 2010; van der Zee et al. 2012; van der Zee et al. 2013; van der Zee et al. 2014; Vejsnæs et al. $2010)$, including the United States (vanEngelsdorp et al. 2007, 2008, 2010, 2011, 2012; Spleen et al. 2013; Steinhauer et al. 2014). Multi-year records are especially important to understanding the variability of losses.

In the USA, surveys have been conducted since the winter of 2006-2007. The surveys asked beekeepers about numbers of living colonies at different points in the year, decreases and increases of colonies, the level of winter loss that they deemed acceptable, the state(s) the colonies were kept in, if the beekeepers moved colonies across state lines, if the colonies were used for almond pollination, and the perceived causes of those losses, including colony collapse disorder (CCD) (vanEngelsdorp et al. 2009). From the previous surveys, the total US winter losses were 32,36 , $29,34,30,22$, and $31 \%$ for the winters of $2006-$ 2007, 2007-2008, 2008-2009, 2009-2010, 2010-2011, 2011-2012, and 2012-2013, respectively (vanEngelsdorp et al. 2007, 2008, 2010, 2011, 2012; Spleen et al. 2013; Steinhauer et al. 2014). Total US summer and annual losses for 2012-2013 were reported as 25 and $45 \%$, respectively (Steinhauer et al. 2014). Acceptable losses of previous US surveys ranged from 13.2 to 17.6 \% (vanEngelsdorp et al. 2010, 2011, 2012; Spleen et al. 2013; Steinhauer et al. 2014).

This study is based on the latest US colony mortality survey conducted by the Bee Informed Partnership (BIP, beeinformed.org). It addresses colony mortality from 1 April 2013 to 1 April 2014. It is the second survey in the series to include summer and annual losses along with winter losses. We include the level of acceptable losses reported by beekeepers and the percent of beekeepers that exceed the level of loss they deem acceptable. The results contain loss comparisons by operation type, losses by state, pollination of almonds, migratory status, and the self-reported causes of death, including the percent of colonies that died with the symptom "no dead bees in the hive or apiary." As in previous surveys, responding beekeepers were categorized by operation type (backyard, sideline, or commercial) based on the number of colonies they managed, as backyard, sideline, and commercial beekeepers tend to have different management practices. Commercial beekeepers are more likely to be migratory, use their colonies to pollinate almonds, have more intensive management practices, and keep colonies in high-density locations that can affect disease transmission and virulence (Royce and Rossignol 1990). Backyard beekeepers tend to be stationary, have fewer colonies, and manage less rigorously. Sideline beekeepers tend to be between the other two groups. Beekeepers were also categorized by state, as reporting the state(s) in which the colonies were kept can help account for differences colony losses due to the climate or regional practices. In addition, as causes of mortality can be multifactorial and vary among operation types and colony location, asking 
beekeepers to report what they think is their primary cause(s) of death can lead to insights about the most influential factors of loss for beekeepers in different regions and demographics.

\section{METHODS}

\subsection{Survey}

The survey to estimate colony losses of 2013 to 2014 was provided online through the Internet platform SelectSurvey.com. Beekeepers were invited to participate via email by distribution through lists maintained by two national beekeeping organizations (American Beekeeping Federation and American Honey Producer's Association), a beekeeping supply company (Brushy Mountain Bee Farm), two honey bee brokers, two beekeeping journals (American Bee Journal and Bee Culture), and two subscription listservs (Catch the Buzz and ABF Alert). An e-mail request to participate in the survey was sent to 8679 beekeepers that signed up to participate on beeinformed.org, responded to a previous BIP survey and indicated their willingness to participate in future surveys, or participated in the USDA Animal Plant Health Inspection Service National Honey Bee Disease Survey and provided their e-mail. All survey requests asked beekeepers to forward the survey on to other beekeepers. Requests to distribute letters were sent to the Apiary Inspectors of America, state extension apiculturists, industry leaders, and to a number of beekeeping clubs, including the Eastern Apicultural Society. To specifically encourage the participation of commercial beekeepers, we conducted surveys over the phone or mailed paper surveys $(n=1200)$ either through BIP or a state apiarist. As our methods for soliciting responses depended on other organizations and requests to pass on the invitation, we are unable to calculate a total number of beekeepers contacted. The survey was not randomly conducted as described by van der Zee et al. 2013, which could lead to bias in the results. To compensate for the potential bias, we used a variety of other contact methods to reach a diverse group of beekeepers and contacted every registered commercial beekeeper.

At the request of several commercial beekeepers and due to the longer than typical winter weather in some states, we extended the survey to encompass the entire month of April. The survey was available online from 1 to 30 April 2014. Paper surveys were mailed on 26
March, and completed surveys returned by 9 May were included in the analyses.

The survey consisted of two parts: the "loss survey" and the "management survey." After completion of the loss survey, beekeepers were given the option to continue to the management survey. Only the responses to the loss survey are addressed in this study. Online Resource 1 contains the loss survey questions and the corresponding definition for valid responses to each question. Loss questions were based on the survey designed by Prevention of honey bee COlony LOSSes (COLOSS), a research group that measures colony losses internationally (van der Zee et al. 2013). However, the definition of colony loss in this survey differs from the COLOSS survey. We consider a colony as "living" if it is "alive on that date, independent of future prospects," while the COLOSS survey takes the future prospects of the colony into account. Definitions for a "colony," "living" colonies, and "increases" are provided in Online Resource 1.

The 2013-2014 survey included the same core questions as the previous years' winter loss surveys and the same summer and annual loss questions as last year's loss survey (Steinhauer et al. 2014). As in the previous US surveys, summer was defined as the period from 1 April 2013 to 1 October 2013, winter from 1 October 2013 to 1 April 2014, and annual from 1 April 2013 to 1 April 2014 (vanEngelsdorp et al. 2007, 2008, 2010, 2011, 2012; Spleen et al. 2013; Steinhauer et al. 2014). New to the current survey were questions 11 , 12, 20, 21, and 22 (Online Resource 1). Winter, summer, and annual are classified as a fixed time period as there is no definable winter in some states. We account for colony increases and decreases during the fixed time periods in the current survey. A fixed winter definition is a deviation from the methods by van der Zee et al. 2013, but the same as the 2010 questionnaire used for countries without a definable winter (van der Zee et al. 2012).

The loss data were edited to remove invalid response (i.e., negative numbers, responses that exceeded 100,000 managed colonies). Duplicate entries were removed, as were entries from non-US respondents. The questionnaire included a multiple choice question with an open entry "other" category, where responses were sorted to either keep the entry as "other" if the cause of death written was effectively different from the listed categories or revised to one of the preexisting categories where appropriate. After the initial validation, three 
subsets of data based on the three time periods were created for the analyses: valid for winter loss, valid for summer loss, and valid for annual loss. These subsets were necessary because not all respondents answered the entire set of loss questions. To be valid in a time period, beekeepers needed to start that time period with at least one colony.

Each beekeeper's set of managed colonies will be referred to as that beekeeper's "operation." To compare different operation sizes, beekeepers were classified into three groups based on the number of living colonies managed on 1 October 2013: "backyard beekeepers" managed 50 or fewer colonies, "sideline beekeepers" managed between 51 and 500 colonies and "commercial beekeepers" managed more than 500 colonies. These classifications are identical to those used in the previous surveys.

\subsection{Statistics}

Total and average colony losses for summer, winter, and the annual period were calculated for all operations based on vanEngelsdorp et al. (2013) and Steinhauer et al. (2014). First, percent colony loss for each time period for each respondent was calculated by dividing the number of colonies the beekeeper lost by the number of colonies at risk in summer, winter, and annual (Online Resource 1, questions 2-5, 5-8, and 2-8, respectively). The total \% loss for each time period (summer, winter, and annual) were calculated by dividing the total number of colonies lost in that time period by the total number of colonies at risk in the same time period and multiplying by 100 . Results from the total $\%$ loss calculations were applied to calculate the average \% loss for each time (summer, winter, and annual). Average losses were calculated by summing all the individual $\%$ losses for that time period, then dividing by the number of respondents for that same time period. All equations can be found in Steinhauer et al. 2014. The $95 \%$ confidence intervals ( $95 \%$ CIs) for the total losses were calculated using a generalized linear model (quasibinomial distribution) (R Development Core Team, 2009; code provided by Y. Brostaux and B.K. Nguyen). The $95 \%$ CI for average losses were calculated using the Wald's formula (see vanEngelsdorp et al. 2013 for details).

Total loss calculations count each individual colony equally, without regard to operation size. This means beekeepers with more colonies have greater influence in the total loss results. For comparison, in the average loss calculations, each beekeeper's operation is counted once, meaning each operation has the same weight whether it is backyard, sideline, or commercial. Total loss calculations are more representative of commercial operations as they manage significantly more colonies compared to backyard and sideline operations. Average loss calculations are more representative of backyard beekeepers as there are more backyard than commercial or sideline operations. Total loss is more informative to compare losses among seasons and among states, and average loss is more informative to compare categories of respondents.

The winter loss data were used to compare operation types (backyard, sideline, commercial), losses by state, migratory status (beekeepers that moved colonies at least once during the year), beekeepers that use their colonies to pollinate almond trees in California, acceptable winter losses, and causes of colony death, including the percent of colonies that died with the symptom "no dead bees in the hive or apiary" (a characteristic associated with CCD). The Kruskal-Wallis rank sum test was used to compare average losses among groups, which, if significant, was followed with a MannWhitney $U$ test (Wilcoxon rank-sum test) for a pairwise test to check for significant differences between groups and a Bonferroni correction for multiple comparisons. All statistics were performed using statistical program $\mathrm{R}$ ( $\mathrm{R}$ version 3.1 .0 (2014-04-10), and all tests used a significance level of $\alpha=0.05$. To report the state losses, we followed the USDA-NASS method of counting colonies of multistate beekeepers in each state in which the beekeeper reported having colonies (USDA-NASS 2014). Multistate beekeepers can be migratory or stationary. If a state had five or fewer respondents, the losses for that state were not reported to preserve the identity of the respondent(s).

\section{RESULTS}

\subsection{Average and total losses}

There were a total of 7425 loss entries (7123 backyard, 190 sideline, and 112 commercial beekeepers) after the data were validated and duplicate responses removed. There were 5962 respondents with valid data in the summer loss data subset, 7189 respondents in the winter loss data subset, and 6105 respondents in the annual loss 
subset. The total number of colonies managed by the respondents on 1 October 2013 was 497,855 or approximately $18.9 \%$ of the 2.64 million total colonies in the nation (USDA-NASS 2014). Of the 7189 valid winter loss respondents, 1994 beekeepers (27.7 \% of all respondents) reported losing no colonies over winter (1984 backyard beekeepers, 7 sideline beekeepers, and 3 commercial beekeepers).

Table I provides a summary of the total number of colonies managed by the respondents at the start and end of each of the time periods, the total colony increases and decreases for each period, and the total and average losses of each period. Over the winter, total colony losses reported were $23.7 \%$ [95 \% CI 23.3-24.1\%] and the average winter losses were $44.8 \%$ [95 \% CI 43.9-45.7\%]. Total summer losses were $19.8 \%$ [95 \% CI 19.3$20.3 \%$, and the summer average losses were $15.1 \%$ [95 \% CI 14.5-15.7\%]. Total annual losses were $34.1 \%$ [95 \% CI 33.6-34.6\%], and the average annual losses were $51.1 \%$ [95\% CI $50.2-51.6 \%]$. Note that different pools of respondents were analyzed for each of the time periods.tgroupa

\subsection{State losses}

States had dramatically different numbers of respondents, ranging from 1 in Puerto Rico to 1080 in Pennsylvania, with a large range of total and average losses. The range in total losses was from 2.3 to $71.1,11.1$ to 71.1 , and 20.1 to $89.7 \%$ for summer, winter, and annual, respectively. Average losses ranged from 4.2 to $24.2,11.1$ to 69.1 , and 24.4 to $72.2 \%$ for summer, winter, and annual, respectively. Online Resource 2 shows images of US maps with the total and average losses plotted for each state and the number of winter loss respondents. To indicate the distribution of multistate beekeepers, we have included the percent of beekeepers that operate exclusively within the state (ranging from 3.2 to $100 \%$ ) and the percent of colonies that were kept exclusively within the state (ranging from 0.04 to $100 \%$ ). As stated in the methods, beekeepers that manage colonies in more than one state were counted in each state. Therefore, states with a small percentage of beekeepers operating exclusively inside the state require caution when interpreting the results. Online Resource 3 summarizes the following for each state: number of respondents and colonies, number of respondents from each operation type in, percent colonies operating exclusively in that state, and the summer, winter and annual losses.

\subsection{Losses by operation type}

Response rates to the survey were different for the three operation types. For the winter loss data subset, $96.0 \%$ of the total number of respondents were backyard beekeepers $(n=6899), 2.6 \%$ were

Table I. A summary of the three loss periods (summer, winter, and annual) of the self-reported colony loss data from 1 April 2013 to 1 April 2014, with the total number of respondents, the total number of colonies on each date, the total number of colonies increases $(+)$ and decreases $(-)$, and the total loss and average loss for each period $(\%)[95 \% \mathrm{CI}]$.

\begin{tabular}{|c|c|c|c|c|c|c|c|c|}
\hline \multirow[t]{2}{*}{ Period } & \multirow[t]{2}{*}{ Number } & \multicolumn{5}{|c|}{ Total number of colonies managed on } & \multirow{2}{*}{$\begin{array}{l}\text { Total loss } \\
(\%)\end{array}$} & \multirow{2}{*}{$\begin{array}{l}\text { Average loss } \\
(\%)\end{array}$} \\
\hline & & $\begin{array}{l}\text { 1 April } \\
2013\end{array}$ & & $\begin{array}{l}1 \text { October } \\
2013\end{array}$ & & $\begin{array}{l}\text { 1 April } \\
2014\end{array}$ & & \\
\hline Summer loss & 5962 & 397,611 & $\begin{array}{l}(+186,361) \\
(-18,509)\end{array}$ & 453,459 & & - & $\begin{array}{l}19.8 \\
{[19.3-20.3]}\end{array}$ & $\begin{array}{l}15.1 \\
{[14.5-15.7]}\end{array}$ \\
\hline Winter loss & 7189 & - & & 497,855 & $\begin{array}{l}(+86,220) \\
(-11,716)\end{array}$ & 436,759 & $\begin{array}{l}23.7 \\
{[23.3-24.1]}\end{array}$ & $\begin{array}{l}44.8 \\
{[43.9-45.7]}\end{array}$ \\
\hline Annual loss & 6105 & 435,662 & $\begin{array}{l}(+197,549) \\
(-23,270)\end{array}$ & 505,003 & $\begin{array}{l}(+91,993) \\
(-13,440)\end{array}$ & 453,525 & $\begin{array}{l}34.1 \\
\quad[33.6-34.6]\end{array}$ & $\begin{array}{l}51.1 \\
{[50.2-51.9]}\end{array}$ \\
\hline
\end{tabular}


sideline beekeepers $(n=186)$, and $1.4 \%$ were commercial beekeepers $(n=104)$. The three different operation types managed very different numbers of colonies. Of the 497,855 colonies managed on 1 October 2013, the backyard beekeepers managed 39,188 colonies $(7.9 \%$ of the total number of colonies), sideline beekeepers managed 27,288 colonies $(5.5 \%)$, and commercial beekeepers managed 431,379 (86.6 \%) (Table II). There was a seasonal difference in the total losses for sideline and backyard beekeepers: more colonies died in the winter compared to the summer. Winter and summer losses for commercial beekeepers were not different. A visualization of the seasonal average losses for each operation type is provided in Figure 1.

There were significant differences in mortality among seasons and operation types (statistics summarized in Online Resource 4). All beekeeper operation types had significantly different average annual losses (Kruskal-Wallis $\chi^{2}=39.2306$, all Mann-Whitney $P<0.05$ ), with backyard beekeepers having the highest losses and commercial beekeepers with the lowest losses (Table II). Comparing the average losses across operation types for summer and winter, only the winter losses of sideline and backyard beekeepers were not different (KruskalWallis $\chi^{2}=61.6678$, Mann-Whitney $P=0.064$ ).

To compare average winter losses of migratory to non-migratory beekeepers and beekeepers that used colonies to pollinate almonds to those that do not pollinate almonds, we performed separate analyses for sideline and commercial beekeepers since the two operation types had significantly different winter losses (Kruskal-Wallis $\chi^{2}=21.6678$, Mann-Whitney $P<0.0001$ ) (Table III). This comparison differs from last year's survey that included both commercial and sideline beekeepers (Steinhauer et al. 2014). Backyard beekeepers were not included due to few being migratory or commercial almond pollinators (1.2 and $0.1 \%$ of backyard beekeepers, respectively). The only significant difference found was migratory sideline beekeepers which had lower losses compared to non-migratory sideline beekeepers (Kruskal-Wallis $\chi^{2}=7.1623$, Mann-Whitney $P=0.007445)$. There was no difference between migratory and non-migratory in commercial groups, but the $P$ value was close to $0.05(P=0.065)$. Losses of sideline beekeepers using their colonies to pollinate almond was not different than non-pollinator losses, but the $P$ value was again close to $0.05(P=0.060)$.

\subsection{Acceptable winter losses}

On average, beekeepers reported that a $19.1 \%$ (95\% CI 18.6-19.5\%) winter loss was acceptable. Separated by operation type, commercial beekeepers had the lowest self-reported average acceptable winter loss of $16.8 \%$ (95\% CI 14.5$19.2 \%$, sideline beekeepers reported an average

Table II. Average and total losses by operation type (total and average loss (\%) [95 \% CI]), including the number of operations included in each analysis, the number of colonies at the beginning of the specified analysis period, and the relative percent of colonies in the respondent pool run by each operation type.

\begin{tabular}{cllllll}
\hline \multicolumn{1}{c}{ Period } & $\begin{array}{c}\text { Operation } \\
\text { type }\end{array}$ & Number & $\begin{array}{c}\text { No. of colonies } \\
\text { (start) }\end{array}$ & $\begin{array}{c}\text { \% Colonies } \\
\text { (start) }\end{array}$ & $\begin{array}{c}\text { Total loss (\%) } \\
{[95 \% \text { CI }]}\end{array}$ & $\begin{array}{c}\text { Average loss (\%) } \\
{[95 \% \text { CI }]}\end{array}$ \\
\hline \multirow{2}{*}{ Summer loss } & Backyard & 5695 & 26,903 & 6.8 & $20.1[19.4-20.8]$ & $15.1[14.5-15.7]$ \\
& Sideline & 164 & 18,357 & 4.6 & $19.1[15.8-22.6]$ & $12.5[10.0-14.9]$ \\
& Commercial & 103 & 352,351 & 88.6 & $19.8[16.6-23.4]$ & $18.7[15.7-21.7]$ \\
Winter loss & Backyard & 6899 & 39,188 & 7.9 & $43.6[42.8-44.3]$ & $45.3[44.4-46.2]$ \\
& Sideline & 186 & 27,288 & 5.5 & $35.5[31.8-39.4]$ & $38.9[34.9-42.8]$ \\
& Commercial & 104 & 431,379 & 86.6 & $21.3[18.6-24.2]$ & $22.7[19.6-25.8]$ \\
Annual loss & Backyard & 5815 & 27,738 & 6.4 & $52.0[51.2-52.8]$ & $51.6[50.7-52.5]$ \\
& Sideline & 180 & 19,470 & 4.5 & $44.6[40.6-48.7]$ & $44.5[40.5-48.4]$ \\
& Commercial & 110 & 388,454 & 89.2 & $32.1[29.1-35.2]$ & $32.6[29.4-37.5]$ \\
\hline
\end{tabular}




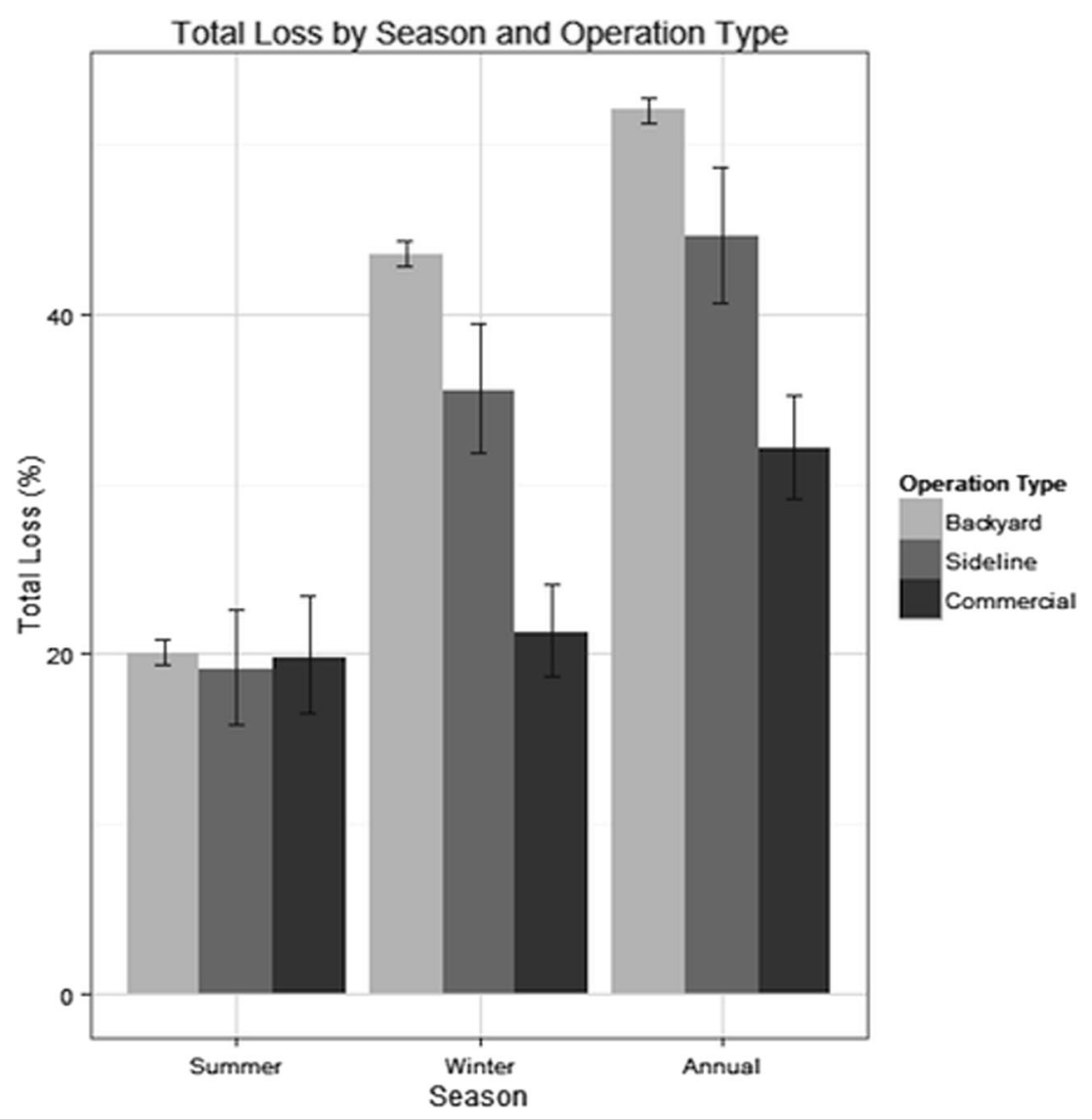

Figure 1. A comparison of the average (\%) summer (1 April 2013 to 1 October 2013), winter (1 October 2013 to 1 April 2014), and annual (1 April 2013 to 1 April 2014) losses (with $95 \%$ CI) of the three beekeeping operation types (backyard, sideline, and commercial).

Table III. Results of a Kruskal-Wallis rank-sum test and followed-up by a Mann-Whitney test used to compare the average winter losses (\%) $[95 \% \mathrm{CI}]$ among commercial and sideline operations that do or do not take their colonies to pollinate almonds in California, and beekeepers that are migratory (moved their bees at least once during the past year) to those that are not.

\begin{tabular}{|c|c|c|c|c|c|c|}
\hline $\begin{array}{l}\text { Operation } \\
\text { type }\end{array}$ & Factor & Selection & Number & $\begin{array}{l}\text { Average winter loss } \\
\quad(\%)[95 \% \mathrm{CI}]\end{array}$ & $\begin{array}{c}\text { Kruskal-Wallis } \\
\text { chi-squared }\end{array}$ & $P$ value \\
\hline \multirow[t]{4}{*}{ Commercial } & Almond pollination & No & 22 & 27.6 [19.3-35.9] & \multirow[t]{2}{*}{1.5348} & \multirow[t]{2}{*}{0.2154} \\
\hline & & Yes & 76 & $22.1[18.7-25.4]$ & & \\
\hline & Migratory & No & 22 & $29.5[21.5-37.5]$ & \multirow[t]{2}{*}{3.3969} & \multirow[t]{2}{*}{0.0653} \\
\hline & & Yes & 76 & 21.5 [18.2-24.9] & & \\
\hline \multirow[t]{4}{*}{ Sideline } & Almond pollination & No & 151 & $40.2[35.8-44.6]$ & \multirow[t]{2}{*}{3.5249} & \multirow[t]{2}{*}{0.0605} \\
\hline & & Yes & 27 & $30.7[20.5-40.9]$ & & \\
\hline & Migratory & No & 135 & $41.7[37.1-46.3]$ & \multirow[t]{2}{*}{7.1623} & \multirow[t]{2}{*}{$0.0075^{*}$} \\
\hline & & Yes & 43 & $29.5[21.7-37.4]$ & & \\
\hline
\end{tabular}

$* P<0.05$, significant 
acceptable loss of $18.4 \%$ (95\% CI 16.2-20.6\%), and backyard beekeepers had the highest level of $19.1 \%$ (95 \% CI 18.7-19.6\%). The self-reported acceptable winter loss ranged from 0 to $100 \%$. We compared each beekeeper's actual winter losses to the loss they reported as acceptable and found that 2447 beekeepers (34.0\% of respondents) had a winter loss that they considered to be acceptable, and 4742 beekeepers $(66.0 \%$ of respondents) exceeded the winter loss they considered acceptable. Beekeepers that were below their self-reported acceptable winter loss had an average winter loss of $2.3 \%$ (95\% CI 2.1-2.5\%). Beekeepers that exceeded what they deemed an acceptable loss had an average winter loss of $66.7 \%$ (95\% CI 65.9-67.5).

Beekeepers that reported that their winter losses compared to last year were lower, same, higher, no bees, or do not know lost had average losses of $19.6 \%$ (95\% CI 18.4-20.7), $38.6 \%$ (95\% CI 36.6-40.7), $66.5 \%$ (95\% CI 65.3$67.7), 44.0 \%$ (95\% CI 41.4-46.5), or $29.5 \%$ (95\% CI 24.5-34.4) of their colonies, respectively (Table IV). All loss level groups had significantly different loss averages except for the comparison between the "same loss" and "do not know" groups (Kruskal-Wallis $\chi^{2}=1543.264$, $d f=4, P<0.0001$; all Mann-Whitney $P<0.05$, except comparison between "same loss" and "do not know").

\subsection{Self-reported causes of winter loss}

In the winter loss data subset, a total of 4903 beekeepers (4635 backyard, 172 sideline, and 96 commercial beekeepers) had losses and reported at least one cause of death. The selected causes of death in order were poor wintering conditions $(n=2237)$, starvation $(n=1774)$, weak in the fall $(n=1610)$, queen failure (956), do not know (921), Varroa destructor $(n=836)$, other $(n=455)$, pesticides $(n=325), \operatorname{CCD}(n=324)$, Nosema spp. $(n=261)$, small hive beetle $(n=250)$, and disaster $(n=100)$. Common causes of death written in the "other" category were wasps $(n=59)$, ventilation/moisture $(n=48)$, wax moth $(n=46)$, swarming $(n=41)$, and robbing $(n=38)$. The relative frequency of responses was separated by operation type to show the relative frequency of the selection of each cause of death (Figure 2). For both backyard and sideline beekeepers, the top three self-reported causes of colony death in order were poor wintering conditions, starvation, and weak colonies. Commercial beekeepers chose queen failure, $V$. destructor, and pesticides. Beekeepers that reported losing colonies to poor wintering conditions, $\mathrm{CCD}$, or did not know reported losing more bees than those who did not report those causes (Kruskal-Wallis $\chi^{2}=286.5315,4.2501$, and 31.2649, respectively, with all Mann-Whitney $P<0.05$ ). Beekeepers that reported losing colonies to queen failure, $V$. destructor, weak in the fall, or "other" had fewer loses compared to beekeepers that did not report those causes (Kruskal-Wallis $\chi^{2}=151.9933$, $26.234,44.018$, and 5.0879, respectively, with all Mann-Whitney $P<0.05$ ). Results and statistics are summarized in Online Resource 5.

For the question that asked for if colonies that died over the winter had the symptom "without dead bees in the hive or apiary," there were a total of 4907 valid responses with 1455 beekeepers reporting having at least one colony that died with the symptom and 3452 reporting the absence of this symptom. We estimate that 46,765 colonies died with this symptom or $34.5 \%$ of the total colonies that died over the winter. This number was estimated using the number of beekeepers reporting the symptom, the percent at which they reported the symptom, and the number of colonies that died over the winter in those beekeepers' operations. Beekeepers that reported the symptom did not have higher losses than those that did not report the symptom (Kruskal-Wallis $\chi^{2}=2.3436$, Mann-Whitney $P=0.1258)$. Commercial beekeepers were 2.9 times more likely to report the symptom compared to backyard beekeepers (Pearson's $\chi^{2}=197.3449, d f=2, P<0.0001$ ).

\section{DISCUSSION}

This is the eighth in a series of surveys estimating annual US colony winter losses since 2006-2007 (vanEngelsdorp et al. 2007, 2008, 2010, 2011, 2012; Spleen et al. 2013; Steinhauer et al. 2014) and the second year to report annual and summer losses (Steinhauer et al. 2014). While the results showed a lower 
Table IV. Comparison of the responses to the survey question "Was your winter loss this year higher or lower than last year?"

\begin{tabular}{lcccc}
\hline $\begin{array}{c}\text { Winter loss } \\
\text { level }\end{array}$ & $\begin{array}{c}\text { No. of backyard } \\
\text { beekeepers }\end{array}$ & $\begin{array}{c}\text { No. of sideline } \\
\text { beekeepers }\end{array}$ & $\begin{array}{c}\text { No. of commercial } \\
\text { beekeepers }\end{array}$ & $\begin{array}{c}\text { Average winter loss (\%) } \\
{[95 \% \text { CI] }}\end{array}$ \\
\hline Lower & 1,604 & 64 & 34 & $19.6[18.4-20.7]$ \\
Same & 1,351 & 24 & 20 & $38.6[36.6-40.7]$ \\
Higher & 2,426 & 82 & 38 & $66.5[65.3-67.7]$ \\
No bees & 1,083 & 2 & 0 & $44.0[41.4-46.5]$ \\
Do not know & 142 & 5 & 5 & $29.5[24.5-34.4]$ \\
\hline
\end{tabular}

The number of respondents in each operation type is provided, along with the overall average winter loss (\%) $[95 \% \mathrm{CI}]$ for each possible response

total winter loss, the average winter loss was among the highest of all the surveys, with a large difference in winter losses among operation types. This year, the survey respondents reported one of the highest acceptable winter loss levels; however, $66 \%$ of beekeepers still exceeded their level of acceptable loss. Summer losses were considerable, emphasizing that surveys should measure annual losses to estimate colony mortality.

\subsection{Average and total losses}

This year's total winter loss of $23.7 \%$ was similar to the lowest winter loss in the 8-year survey set of 22.5\% in 2011-2012 (Spleen et al. 2013). Even with this year of lower loss, the average total winter loss of all the US surveys is $29.4 \%$. This year's average winter loss of $44.8 \%$ was the same as the highest average winter loss of the previous seven surveys of $44.8 \%$ that occurred in 2012-

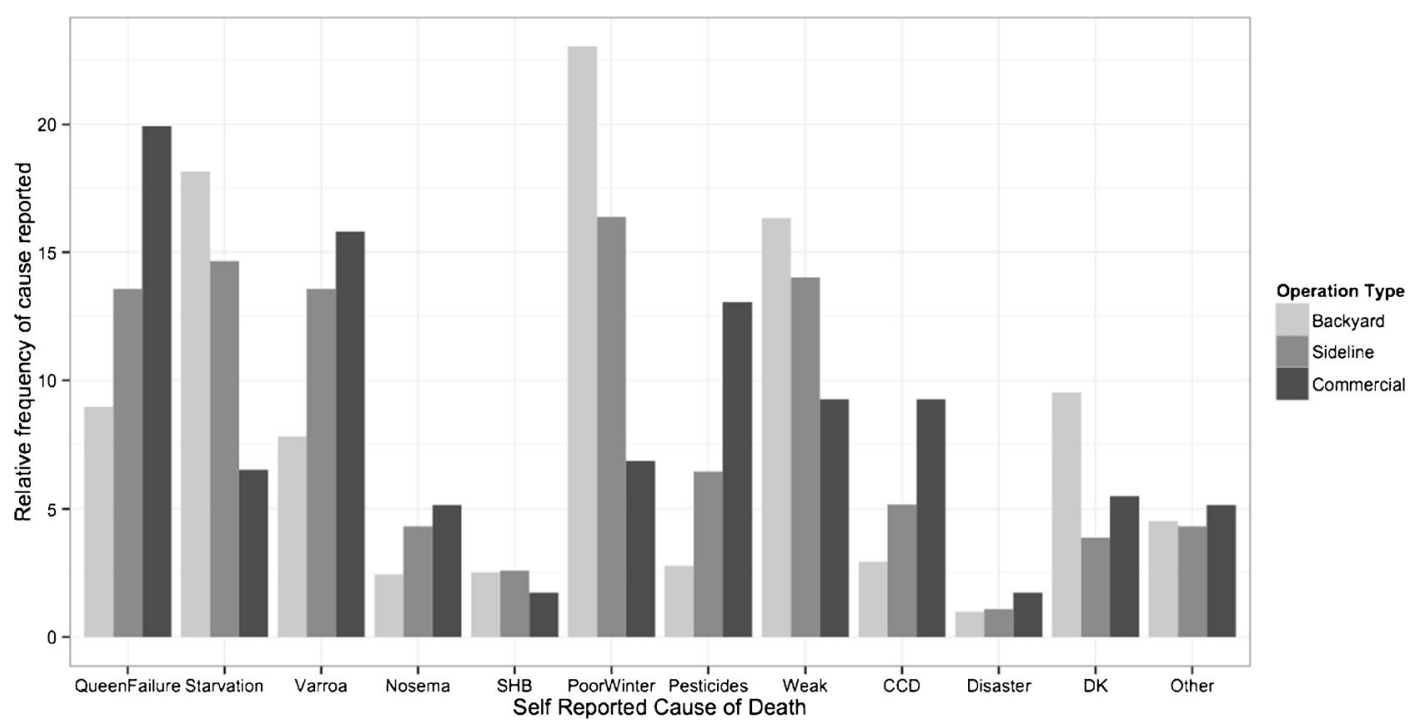

Figure 2. The relative frequency of the most prominent causes of colony winter mortality as chosen by the survey respondents and separated by operation type (backyard, sideline, and commercial). Respondents were able to choose more than one cause of death. $S H B$ small hive beetle, $C C D$ colony collapse disorder, $D K$ do not know, Disaster natural disaster and alike (e.g. flood and bear). 
2013 (Steinhauer et al. 2014). In other countries, beekeepers are also having high winter losses. In 2008-2009, losses ranged from 6.3 to $21.7 \%$ for Austria, Belgium, Denmark, Germany, Ireland, Italy, Netherlands, Norway, Poland, Sweden, Switzerland, and the UK (van der Zee et al. 2012). The following year in 2009-2010, losses were higher for all the countries polled with a range from 8.0 to $37.8 \%$ (van der Zee et al. 2012). Caution needs to be used when making this comparison as these losses do not all have a standard winter loss time frame. Instead, beekeepers were asked to define the winter period on their own, as compared to US survey that defined "winter" as the 6-month period between 1 October and 1 April. High winter losses (20-50\% total losses) have also been reported in other years in Italy (Mutinelli et al. 2010), Denmark (Vejsnæs et al. 2010), Austria and South Tyroll (Brodschneider et al. 2010), Scotland (Gray et al. 2010), England (Aston 2010), Israel (Soroker et al. 2010), Switzerland (Charrière and Neumann 2010), and South Africa (Pirk et al. 2014). Not all losses have been high. Moderate winter losses of about $10 \%$ have been reported in Bulgaria (Topolska et al. 2010) and Norway (Dahle 2010). Low losses (under $5 \%$ ) have been reported in China and various other regions within countries (van der Zee et al. 2012).

As demonstrated by the 2012-2013 survey (Steinhauer et al. 2014), winter losses alone do not provide the full picture of yearly colony mortality. Many regions within the US lack a temperate winter, so losses that occur may not have to do with winter. In 2012-2013, the total winter losses were $30.6 \%$, with a $25.3 \%$ total summer loss, and a $45.2 \%$ annual total loss. If losses were not assessed over the full year, the winter losses would have grossly underestimated the total yearly mortality. Summer losses in other regions have been low (under $5 \%$ ) (Dahle 2010; Gray et al. 2010; Peterson et al. 2010; van der Zee 2010), or higher and varied by region and year (Gray et al. 2010; Mutinelli et al. 2010).

\subsection{State losses}

The USA has a varied climate range that likely affects the loss rate in the different states, especially for stationary beekeepers.
The winter in the Midwest in 2013-2014 was one of the coldest on record and could be reflected in the highest loss averages recorded in that region. However, the Midwest region tends to have a higher average winter loss in other years as well (Steinhauer et al. 2014), which may indicate the importance of preparing colonies for winter. Correlating losses with US weather data should be further investigated. Participation levels varied widely from state to state, which could lead to bias in loss calculations at the state level. This phenomenon is not unique to the USA, as other researchers have seen this high level of variation among regions within and among other countries (van der Zee et al. 2012).

\subsection{Losses by operation type}

While commercial beekeepers manage many colonies and move their bees, they do not appear to have higher losses than the other two beekeeper groups. In this survey, commercial beekeepers had lower winter and annual losses. In the previous US surveys, commercial beekeepers either had the same level of winter loss (vanEngelsdorp et al. 2007, 2008, 2012; Spleen et al. 2013) or significantly lower losses (vanEngelsdorp et al. 2010, 2011; Steinhauer et al. 2014) than backyard beekeepers. Sideline beekeepers were not different from commercial or backyard beekeepers in the rest of the survey years, except for 2012-2013 when losses were higher than commercial beekeeper losses and lower than backyard beekeepers losses (Steinhauer et al. 2014) and in 2009-2010 when losses were higher than commercial beekeeper losses (vanEngelsdorp et al. 2011). This trend of lower losses for larger operation extends out of the USA. A survey of 19 mostly European countries also found that the larger operations (150 colonies or more) had significantly lower losses than the smaller operations (van der Zee et al. 2014).

The dramatic difference between the total winter loss of $23.7 \%$ and the average winter loss of $44.8 \%$ was largely due to the total loss being more reflective of the commercial 
losses and the average loss reflecting the backyard beekeeper losses. Commercial beekeepers have the majority of colonies and more influence over the total loss, and backyard beekeepers are the majority of the survey respondents and have more influence over the average loss calculations. Commercial beekeepers are generally migratory and keep their bees out of the temperate zones in winter. In addition, backyard beekeepers may be less willing to treat their bees for $V$. destructor, which could result in high winter losses (Dainat et al. 2012b; Le Conte et al. 2010; vanEngelsdorp and Meixner 2010).

In this survey and all previous US surveys, beekeepers that are migratory or use their colonies to pollinate almonds had equal or lower losses compared to beekeepers that do not do these practices (vanEngelsdorp et al. 2007, 2008, 2010, 2011, 2012; Spleen et al. 2013; Steinhauer et al. 2014). These results suggest that moving colonies or pollinating almonds does not increase the chance of mortality as some have suggested. In fact, there may be a benefit associated with pollinating almonds or the management practices employed by beekeepers that pollinate almonds better protect colonies. This may not be applicable to other countries, especially if the causes of mortality are different, as a survey in South Africa found higher losses among the migratory beekeepers (Pirk et al. 2014).

\subsection{Acceptable winter losses}

Even though this year's total winter losses were lower than the previous 7-year average of $30 \%$ total winter loss, $66 \%$ of survey respondents still had losses higher than the average $19 \%$ loss they reported as acceptable. This $19 \%$ acceptable loss was the highest reported acceptable loss of all the past US surveys, although it was similar to the $17.6 \%$ acceptable loss reported in 20082009 (vanEngelsdorp et al. 2010). Otherwise, the previous acceptable loss range reported from 2009-2010 to 2012-2013 ranged from 13.2 to $14.6 \%$ (vanEngelsdorp et al. 2011,
2012; Spleen et al. 2013; Steinhauer et al. 2014). This higher reported level of acceptable loss could be due in part to influence of the media focusing on high honey bee colony losses or to beekeepers becoming more accustomed to higher losses. For comparison, the acceptable average winter colony loss was reported to be $10 \%$ in both Switzerland (Charrière and Neumann 2010) and Germany (Genersch et al. 2010), and $12 \%$ for Denmark (Vejsnæs et al. 2010).

\subsection{Self-reported causes of winter loss}

Beekeepers were asked to choose the factors that had the greatest effect on their colony death over the winter. In previous US surveys, the most common causes of colony death reported by beekeepers were queen failure, $V$. destructor, starvation, weak in the fall, pesticides, poor wintering conditions, and CCD (vanEngelsdorp et al. 2007, 2008, 2010, 2011, 2012; Spleen et al. 2013; Steinhauer et al. 2014). In this survey, backyard and sideline beekeepers both chose poor wintering conditions, starvation and weak colonies, in that order. Commercial beekeepers chose queen failure, $V$. destructor, pesticides, and $\mathrm{CCD}$, in that order. The ranked list of causes of death for commercial beekeepers was identical to the ranked list of causes of death for commercial beekeepers in 2012-2013 (Steinhauer et al. 2014). In 20122013, the backyard beekeepers chose weak, starvation, and that they did not know (Steinhauer et al. 2014). Poor winter was ranked sixth in 2012-2013. The high ranking of poor winter this year could point to a driver of high colony mortality in temperate zones; however, the backyard average winter loss in 2012-2013 (45.4\%) was very similar to the backyard average winter loss in 20132014 (45.3 \%). Further investigation into the regional differences in colony loss could shed light on this apparent discrepancy.

The survey question asking for a percentage of colonies that are "lost without dead bees in the hive or apiary" is a proxy question for $\mathrm{CCD}$ as it is one of the classically 
described symptoms (vanEngelsdorp et al. 2009). In previous US surveys, beekeepers reporting that at least one colony died with the CCD symptom lost significantly more colonies compared to beekeepers that did not report losing colonies with the symptom. However, this year beekeepers that reported the CCD symptom did not have higher losses. Interestingly, when asked directly if a cause of loss was CCD, beekeepers selecting $\mathrm{CCD}$ had higher losses compared to beekeepers that did not select $\mathrm{CCD}$ as a cause of death. This could be due to confusion of the definition of CCD, which may have been caused in part by the high media attention. In Europe, beekeepers that reported losing colonies with no dead bees present lost more colonies than those beekeepers that did not report the symptom (van der Zee et al. 2014).

\subsection{Potential sources of bias}

There are a few potential sources of bias that could affect the results of this survey. One source could be that the survey was not random as described by van der Zee et al. 2013, which may result in bias in the type of respondents. Beekeepers with access to a computer and those that are more Internet-literate may be a larger portion of our respondents. To help compensate for the potential bias, we mailed paper surveys to every registered commercial beekeeper in the USA and any beekeeper that requested a paper copy. We also widened our respondent pool by providing information in beekeeping journals, a beekeeping supply company, and at meetings.

Bias could be introduced through the location and type of the respondents. Some regions had a lower number of respondents, which could bias the results. In future surveys an emphasis should be made on recruiting more beekeeper participants from areas with low respondents, like Puerto Rico where there was only a single voice, to decrease the state-to-state response bias. Differences among this survey and previous surveys could be due to a difference in the respondent pool. Fewer commercial beekeepers participated in this year's survey ( $n=112,1.5 \%$ of respondents) compared to last year ( $n=135,2.1 \%$ of respondents) (Steinhauer et al. 2014). This could influence the estimation of total losses. There is a possibility that beekeepers with higher losses were more likely to take the time to do the survey. This year had one of the lowest total colony losses, meaning that it is unlikely that commercial beekeepers that had high losses were more likely to respond. However, this survey also had one of the highest average losses, which could mean that backyard beekeepers with higher losses were more likely to fill out the survey. This could result in bias in the reported average losses.

There is a possibility for bias as different respondents could interpret the survey differently or if they had poor recollection of the past. There was no definition for the potential cause of death "weak in the fall" or "poor winter," which could lead to differences in interpretation. The survey was designed to ask questions about the number of living colonies a beekeeper has on a specific date and not about the number of colonies that died. The definition of a "living" was provided, but there may be beekeepers that interrupted the definition of "living" differently. For example, if a colony had a very small population or no queen, a beekeeper may consider it to be not living since the chances of survival are small. Results of the survey could also be altered by recall bias, as the survey asked beekeepers to remember the past.

\subsection{Conclusions}

This study highlights the benefits of performing multiyear surveys to better understand yearly trends. It also demonstrates the importance of considering the individual operation types separately and reporting annual and season-specific losses to best represent the colony losses of the beekeeping industry. Even in a relatively low winter loss year, beekeepers still lost $34 \%$ of their colonies over the full year. Last year, beekeepers lost close to $45 \%$ of their colonies over the full year (Steinhauer et al. 2014). Total winter losses were lower this year, but beekeepers are still experiencing unacceptably high losses. 


\section{ACKNOWLEDGMENTS}

We thank all respondents for their participation. We thank Brian Decker, Heather Eversole, Rachel Fahey, Andrew Garavito, and Meghan McConnell for entering the paper surveys into the database. Our gratitude goes out to the many beekeeping organizations, industry leaders, and beekeeping clubs that forwarded our appeal for participation emails. A special thank you is owed to USDA APHIS, the Apiary Inspectors of America, Eastern Apiculture Society, the American Honey Producers Association, the American Beekeeping Federation, Brushy Mountain Bee Farm, Bee Culture magazine, and American Bee Journal for sending out participation requests to their online audiences. This project was funded by a Coordinated Agricultural Project (CAP) grant from US Department of Agriculture-National Institute of Food and Agriculture (USDA-NIFA): the Bee Informed Partnership and includes, in addition to several of the authors, Marla Spivak, Angela Spleen, Jerry Hayes, Robert Snyder, Ben Sallman, Liana Teigen, Ellen Topitzhofer, Dan Wyns, Danielle Downey, Lauren Rusert, Ed Levi, Shayne Madella, Grace Kunkel, Marjorie Gurganus, Karen Roccasecca, and Robyn Underwood, and the USDA-ARS Areawide Program on Bee Health. Thank you to the reviewers for the helpful comments.

OPEN ACCESS This article is distributed under the terms of the Creative Commons Attribution License which permits any use, distribution, and reproduction in any medium, provided the original author(s) and the source are credited.

Enquête nationale sur les pertes annuelles de colonies d'abeilles aux Etats-Unis entre 2013-2014

Apis mellifera / mortalité / pertes de colonie / enquête nationale

Eine nationale Übersicht bewirtschafteter Honigbienenvölker in 2013-2014 zu jährlichen Völkerverlusten in den USA

\section{Apis mellifera / Mortalität / USA / Übersicht / Völkerverluste}

\section{REFERENCES}

Aizen, M., Garibaldi, L., Cunningham, S., Klein, A.M. (2008) Long-term global trends in crop yield and production reveal no current pollination shortage but increasing pollinator dependency. Curr. Biol. 18(20), $1572-1575$

Aizen, M., Harder, L.D. (2009) The global stock of domesticated honey bees is growing slower than agricultural demand for pollination. Curr. Biol. 19 (11), 915-918

Aston, D. (2010) Honey bee winter loss survey for England, 2007-8. J. Apic. Res. 49 (1), 111-112

Berthoud, H., Imdorf, A., Haueter, M., Radloff, S., Neumann, P. (2010) Virus infections and winter losses of honey bee colonies (Apis mellifera). J. Apic. Res. 49, 60-65

Brodschneider, R., Moosbeckhofer, R., Crailsheim, K. (2010) Surveys as a tool to record winter losses of honey bee colonies: a two year case study in Austria and South Tyrol. J. Apic. Res. 49(1), 23-30

Charrière, J.-D., Neumann, P. (2010) Surveys to estimate colony losses in Switzerland. J. Apic. Res. 49 (1), 132-133

Clermont, A., Eickermann, M., Kraus, F., Georges, C., Hoffmann, L., Beyer, M. (2014) A survey on some factors potentially affecting losses of managed honey bee colonies in Luxembourg over the winters 2010/ 2011 and 2011/2012 J. Apic. Res. 53 (1), 43-56

Dainat, B., Evans, J.D., Chen, Y.P., Gauthier, L., Neumann, P. (2012a) Dead or alive: deformed wing virus and Varroa destructor reduce the life span of winter honeybees. Appl. Environ. Microbiol. 78(4), 981-987

Dainat, B., Evans, J.D., Chen, Y.P., Gauthier, L., Neumann, P. (2012b) Predictive Markers of Honey Bee Colony Collapse. PLoS One 7 (2), e32151

Dahle, B. (2010) The role of Varroa destructor for honey bee colony losses in Norway. J. Apic. Res. 49(1), 124-125

Ellis, J.D., Evans, J.D., Pettis, J. (2010) Colony losses, managed colony population decline, and Colony Collapse Disorder in the United States. J. Apic. Res. 49 (1), 134-136

Gajger, I.T., Tomljanovic, Z., Petrinec, Z. (2010) Monitoring health status of Croatian honey bee colonies and possible reasons for winter losses. J. Apic. Res. 49(1), 107-108

Genersch, E., von der Ohe, W., Kaatz, H., Schroeder, A., Otten, C., et al. (2010) The German bee monitoring project: a long term study to understand periodically high winter losses of honey bee colonies. Apidologie 41 (3), 332-352

Gray, A., Peterson, M., Teale, A. (2010) An update on recent colony losses in Scotland from a sample survey covering 2006-2008. J. Apic. Res. 49(1), 129-131

Hatjina, F., Bouga, M., Karatasou, A., Kontothanasi, A., Charistos, L., et al. (2010) Data on honey bee losses in Greece: a preliminary note. J. Apic. Res. 49 (1), 116118

Ivanova, E.N., Petrov, P.P. (2010) Regional differences in honey bee winter losses in Bulgaria during the period 2006-9. J. Apic. Res. 49(1), 102-103

Le Conte, Y., Ellis, M., Ritter, W. (2010) Varroa mites and honey bee health: can Varroa explain part of the colony losses? Apidologie 41 (3), 353-363 
Mutinelli, F., Costa, C., Lodesani, M., Baggio, A., Medrzycki, P., et al. (2010) Honey bee colony losses in Italy. J. Apic. Res. 49(1), 119-120

Neumann, P., Carreck, N.L. (2010) Honey bee colony losses. J. Apic. Res. 49(1), 1-6

Nguyyen, B.K., Mignon, J., Laget, D., De Graaf, D.C., Jacobs, F.J., et al. (2010) Honey bee colony losses in Belgium during the 2008-9 winter. J. Apic. Res. 49 (4), 337-339

Peterson, M., Gray, A., Teale, A. (2010) Colony losses in Scotland in 2004-2006 from a sample survey. J. Apic. Res. 48(2), 145-146

Pirk, C.W.W., Human, H., Crewe, R.M., vanEngelsdorp, D. (2014) A survey of managed honey bee colony losses in the Republic of South Africa-2009 to 2011. J. Apic. Res. 53 (1), 35-42

Potts, S.G., Biesmeijer, J.C., Kremen, C., Neumann, P., Schweiger, O., Kunin, W.E. (2010a) Global pollinator declines: trends, impacts and drivers. Trends Ecol. Evol. 25(6), 345-353

Potts, S., Roberts, S., Dean, R., Marris, G., Brown, M., et al. (2010b) Declines of managed honey bees and beekeepers in Europe. J. Apic. Res. 49 (1), 15-22

Royce, L.A., Rossignol, P.A. (1990) Epidemiology of honey bee parasites. Parasitol. Today 6(11), 348-353

Soroker, V., Hetzroni, A., Yakobson, B., David, D., David, A., et al. (2010) Evaluation of colony losses in Israel in relation to the incidence of pathogens and pests. Apidologie 42, 192-199

Spleen, A.M., Lengerich, E.J., Rennich, K., Caron, D., Rose, R., et al. (2013) A national survey of managed honey bee 2011-12 winter colony losses in the United States : results from the Bee Informed Partnership. J. Apic. Res. 52 (2), 44-53

Steinhauer, N.A., Rennich, K., Wilson, M.E., Caron, D.M., Lengerich, E.J., et al. (2014) A national survey of managed honey bee 2012-2013 annual colony losses in the USA: results from the Bee Informed Partnership 2012-2013. J. Apic. Res. 53 (1), 1-18

Topolska, G., Gajda, A., Pohorecka, K., Bober, A., Kasprzak, S., et al. (2010) Winter colony losses in Poland. J. Apic. Res. 49 (1), 126-128

United States Department of Agriculture - National Agriculture Statistics Service (USDA-NASS) (2007) Honey. Department of Agriculture; Washington DC, USA. 4 pp

United States Department of Agriculture - National Agriculture Statistics Service (USDA-NASS (2014) Honey. Department of Agriculture; Washington DC, USA. 6 pp

Vejsnæs, F., Nielsen, S.L., Kryger, P. (2010) Factors involved in the recent increase in colony losses in Denmark. J. Apic. Res. 49(1), 109-110 van der Zee, R. (2010) Colony losses in the Netherlands. J. Apic. Res. 49 (1), 121-123

van der Zee, R., Pisa, L., Andonov, S., Brodschneider, R., Charriere, J.D., et al. (2012) Managed honey bee colony losses in Canada, China, Europe, Israel and Turkey, for the winters of 2008-9 and 1009-10. J. Apic. Res. 51 (1), 100-114

van der Zee, R., Gray, A., Holzmann, C., Pisa, L., Brodschneider, R., et al. (2013) Standard survey methods for estimating colony losses and explanatory risk factors in Apis mellifera. J. Apic. Res. 52 (4), 1-36

van der Zee, R., Brodschneider, R., Brusbardis, V., Charrire, J.-D., Chlebo, R., et al. (2014) Results of international standardised beekeeper surveys of colony losses for winter 2012-2013: analysis of winter loss rates and mixed effects modelling of risk factors for winter loss. J. Apic. Res. 53 (1), 19-34

vanEngelsdorp, D., Underwood, R., Caron, D., Hayes Jr., J. (2007) An estimate of managed colony losses in the winter of 2006-2007: a report commissioned by the Apiary Inspectors of America. Am. Bee J. 147, 599603

vanEngelsdorp, D., Hayes Jr., J., Underwood, R.M., Pettis, J. (2008) A Survey of Honey Bee Colony Losses in the U.S., Fall 2007 to Spring 2008. PLoS One . doi:10.1371/journal.pone.0004071

vanEngelsdorp, D., Evans, J.D., Saegerman, C., Mullin, C., Haubruge, E., et al. (2009) Colony collapse disorder: a descriptive study. PLoS One . doi:10.1371/ journal.pone.0006481

vanEngelsdorp, D., Hayes, J., Underwood, R., Pettis, J. (2010) A survey of honey bee colony losses in the United States, fall 2008 to spring 2009. J. Apic. Res. 49 (1), 7-14

vanEngelsdorp, D., Meixner, M.D. (2010) A historical review of managed honey bee populations in Europe and the United States and the factors that may affect them. J. Invertebr. Pathol. 103, S80-S95

vanEngelsdorp, D., Hayes Jr., J., Underwood, R.M., Caron, D., Pettis, J.S. (2011) A survey of honey bee colony losses in the United States, fall 2009 to spring 2010. J. Apic. Res. 50 (1), 1-10

vanEngelsdorp, D., Caron, D., Hayes, J., Underwood, R., Henson, M., et al. (2012) A national survey of managed honey bee 2010-11 winter colony losses in the USA: results from the Bee Informed Partnership. J. Apic. Res. 51 (1), 115-124

vanEngelsdorp, D., Lengerich, E., Spleen, A., Dainat, B., Cresswell, J., et al. (2013) Standard epidemiological methods to understand and improve Apis mellifera health. J. Apic. Res. 52 (4), 1-16 